\title{
Predictors of one-year mortality after hospitalization for an exacerbation of COPD
}

\author{
Cristóbal Esteban ${ }^{1,5^{*}}$, Ady Castro-Acosta ${ }^{2,3}$, Carlos Jose Alvarez-Martínez ${ }^{2,3}$, Alberto Capelastegui ${ }^{1}$, \\ José Luis López-Campos ${ }^{4}$ and Francisco Pozo-Rodriguez ${ }^{2,3}$
}

\begin{abstract}
Background: Hospitalization for a severe exacerbation of COPD (eCOPD) is an important event in the natural history of COPD. Identifying factors related to mortality 1 year after hospitalization could help determine interventions to reduce mortality.

Methods: In a prospective, observational, multicentre study, we evaluated data from two cohorts: the Spanish audit of hospital COPD exacerbation care (our derivation sample) and the Spanish cohort of the European audit of COPD exacerbation care (our validation sample). The endpoint was all-cause mortality. Mortality was determined by local research managers of the participating hospitals and matched the official national index records in Spain.

Results: In the multivariate analysis, factors independently related to an increase in mortality were older age, cardio-cerebro-vascular and/or dementia comorbidities, $\mathrm{PaCO} 2>55 \mathrm{mmHg}$ measured at emergency department arrival, hospitalizations for COPD exacerbations in the previous year, and hospital characteristics. The area under the receiver-operating curve for this model was 0.75 in the derivation cohort and 0.76 in the validation cohort.

Conclusion: One-year mortality following the index hospitalization for an exacerbation of COPD was related to clinical characteristics of the patient and of the index event, previous events of similar severity, and characteristics of the hospital where the patient was treated.
\end{abstract}

Keywords: Pulmonary disease, Chronic obstructive, Hospitalization, Mortality

\section{Background}

Hospitalization for a severe exacerbation of chronic obstructive pulmonary disease (eCOPD) is an important event in the natural history of this disease. Approximately half of the patients admitted for an eCOPD die within 4 years [1]. Identifying factors associated with mid-term mortality ( 1 year) after hospitalization for an eCOPD could provide tools for more targeted evaluation of these patients and interventions to prevent premature death.

Several studies designed for that purpose have yielded variable or conflicting results $[2,3]$. These divergent results can largely be attributed to study methodology, such as the patient population (recruited from the medical ward or from intermediate or intensive care), source of the data (prospective studies, retrospective studies, or

\footnotetext{
* Correspondence: cristobal.est@gmail.com

${ }^{1}$ Pulmonary Service, Galdakao-Usansolo Hospital, Galdakao, Bizkaia, Spain ${ }^{5}$ Network and Health Services Research Chronic Diseases (REDISSEC), Bilbao, Bizkaia, Spain

Full list of author information is available at the end of the article
}

computerized databases), variables studied, duration of follow-up, and organizational and administrative distribution of hospital resources. Another source of uncertainty is whether indices used among patients with stable COPD have the same prognostic capacity when used in those admitted to the hospital $[4,5]$.

The aim of this study was to determine predictors of one-year mortality in patients hospitalized for an eCOPD following discharge for the index event.

\section{Methods}

The Cohorte Española de EPOC Avanzada (CEPA) is a prospective observational study designed to examine factors associated with one-year mortality among patients hospitalized for an eCOPD.

CEPA includes patients from two separate cohorts. One, defined as the derivation cohort, is a sample of patients from the Spanish COPD Audit [6]. The other, defined as the validation cohort, is from the Spanish sample of the 
European COPD Audit [7]. The methodology of both studies has been described in detail elsewhere [6,7].

The Spanish COPD Audit was a cross-sectional study with prospective non-interventional case ascertainment of consecutive eCOPD hospital admissions for the 8-week period from November 1, 2008 to December 31, 2008. Patients were included in the cohort following a two-step process. Reports of all patients admitted to the hospital following an emergency department (ED) visit were reviewed daily to identify one or more of 13 clinical conditions compatible with the diagnosis of eCOPD. These patients were labelled as interim/possible eCOPD cases. They were assessed again at hospital discharge against a list of definite inclusion and exclusion criteria to identify patients with a clinical diagnosis of eCOPD. Those who qualified were labelled as definite eCOPD cases [6]. A total of 32 hospitals completed a one-year follow-up of their patients and were included in our study.

The European Respiratory Society COPD audit was designed as a pilot study to evaluate clinical practice variability as well as clinical and organizational factors associated with outcomes for COPD-related hospital admissions across Europe. This prospective, observational, non-interventional cohort trial was conducted during the 8-week period from January 1, 2011 and February 28, 2011 in 74 hospitals [7].

In both studies, all consecutive cases admitted to the participant hospitals due to an eCOPD were identified and information on clinical practice was gathered. Each patient was included only once in the study.

Comorbidities were standardized recorded from the clinical record of every patient, including any new one diagnosed during the index event. The Charlson index was used as a reference [8].

All the hospitals participating in the studies were asked to complete cross-sectional surveys of the resources and organization they devoted to COPD acute care. The survey included questions related both to the hospital and to the respiratory unit resources.

Mortality was determined by local research managers of the participating hospitals and matched the official national index records in Spain.

The study was approved by Instituto de Salud Carlos III CEI PI 30_2011-v4 and hospital participation in the two cohorts was approved by the ethics committees of the participating hospitals. All participants provided written informed consent. To allow for patient-level analyses, patient data was protected and dissociated.

\section{Statistical analysis}

Descriptive statistics of sociodemographic and clinical variables were calculated using means and standard deviations (SD) for quantitative data; frequencies and percentages were used for categorical variables. The
Spanish cohort represented our derivation cohort and the European cohort the validation cohort.

A univariate analysis was undertaken in the derivation sample to determine variables that were predictors of oneyear mortality (patients who died during the admission were excluded from the analysis). Student's $t$ test (or the Wilcoxon test if normality was rejected) was used for continuous variables, while Chi-square and Fisher's exact tests were used for categorical variables. In the multivariate analysis, generalized linear mixed models were used so as to perform a multilevel multivariable analysis adjusted by hospital, with one-year mortality as the dependent dichotomous variable. The predictive accuracy of the model was determined by calculating the area under the receiveroperating curve (AUC).

The model developed in the derivation cohort was tested in the validation cohort to compare the predictive accuracy of the model by means of comparisons of their AUCs.

We also evaluated the independent influence of the hospital setting both models and determined which hospital characteristics were predictors of mortality.

All effects were deemed statistically significant at $p<$ 0.05 . All statistical analyses were performed using SAS System, version 9.2 (SAS Institute, Inc., Carey, NC).

\section{Results}

A sample of 1420 patients from the Spanish COPD Audit was included in the derivation cohort. Mean patient age was 73 years, $89 \%$ were men, $24.6 \%$ were current smokers, $43 \%$ had a Charlson Comorbidity Index higher than 3 , and $74.6 \%$ had previously been admitted for an eCOPD (Table 1). The in-hospital mortality for that cohort was $5 \%$.

The validation cohort included a sample of 3949 patients from the European COPD Audit. Compared to the derivation cohort, the validation cohort included more women (10.2 vs $14.5 \%)$, had a lower Charlson Comorbidity Index, and statistically significant differences were observed in the percentages of cardiovascular, cerebrovascular, and peripheral vascular disease between the two cohorts (Table 1). The in-hospital mortality for that cohort was $4.3 \%$.

In the univariate analysis, statistically significant differences were observed between patients who had died within 1 year of the index hospitalization and those who had not, in age, smoking habit, Charlson Comorbidity Index, and presence of specific comorbidities such as cardiovascular disease, heart failure, peripheral vascular disease, cerebrovascular disease and dementia, previous eCOPD admissions, number of eCOPD admissions in the previous year, level of airway severity obstruction (FEV1\% and Global Initiative for Chronic Obstructive Lung Disease [GOLD] stages of obstruction) and $\mathrm{PaCO} 2$ 
Table 1 Descriptive statistics of the COPD derivation and validation cohorts

\begin{tabular}{|c|c|c|c|}
\hline & Derivation $n=1420$ & Validation $n=3949$ & $p$-value \\
\hline$\overline{\mathrm{Age}^{\mathrm{a}}}$ & $73.4(10.0)$ & $72.7(10.7)$ & 0.07 \\
\hline Sex (\% male) & $1275(89.8)$ & $3375(85.5)$ & $<0.0001$ \\
\hline FEV1\% & $45.2(16.2)$ & $45.3(16.6)$ & 0.76 \\
\hline FEV1\%/FVC & $52.5(13.4)$ & $52.5(12.9)$ & 0.79 \\
\hline FEV1\% categories & & & $<0.0001$ \\
\hline$\geq 80 \%$ & $33(3.8)$ & $62(2.5)$ & \\
\hline$<80->50$ & $272(31.2)$ & $778(31.0)$ & \\
\hline$<50->30$ & $217(24.3)$ & $1187(47.3)$ & \\
\hline$\leq 30$ & $351(40.2)$ & $482(19.2)$ & \\
\hline Body Mass Index ${ }^{a}$ & $27.9(5.3)$ & $27.8(5.7)$ & 0.35 \\
\hline Smoking habit & & & 0.34 \\
\hline - Ever smoker & $52(4.3)$ & $182(4.9)$ & \\
\hline - Current smoker & $343(28.2)$ & $977(26.3)$ & \\
\hline - Ex-smoker & $822(67.5)$ & $2554(68.8)$ & \\
\hline Cigarette pack-years $^{a}$ & $55,82(29.0)$ & $51,99(30.3)$ & 0.003 \\
\hline Charlson Comorbidity Index ${ }^{a}$ & $2,70(1.8)$ & $1,79(1.7)$ & $<0.0001$ \\
\hline $1-2$ & $795(56.0)$ & $2865(72.5)$ & \\
\hline$\geq 3$ & $625(44.0)$ & $1084(27.4)$ & \\
\hline Ischaemic heart disease & $205(15.7)$ & $505(12.8)$ & 0.008 \\
\hline Cardiac failure & $299(23.0)$ & $810(20.5)$ & 0.07 \\
\hline Peripheral vascular disease & $221(17.2)$ & $494(12.5)$ & $<0.0001$ \\
\hline Cerebrovascular disease & $146(11.3)$ & $380(9.6)$ & 0.09 \\
\hline Cardiac-Cerebro-Peripheral vascular disease & $608(46.2)$ & $2217(44.9)$ & 0.41 \\
\hline Dementia & $138(3,49)$ & $52(4,04)$ & 0.36 \\
\hline Diabetes mellitus & $359(26.2)$ & $1032(26.1)$ & 0.95 \\
\hline Previous COPD hospitalization & $1065(76.7)$ & $1881(51.3)$ & $<0.0001$ \\
\hline Mean of COPD-related admissions in the previous year & $1.92(2.0)$ & $1.17(1.8)$ & $<0.0001$ \\
\hline $\mathrm{pH}$ at arrival & $7.40(0.1)$ & $7.40(0.1)$ & 0.12 \\
\hline Acidaemia during admission & $258(19.3)$ & NA & \\
\hline $\mathrm{PaO} 2$ at arrival ${ }^{\mathrm{a}}$ & $59.1(15.6)$ & $60.4(21.3)$ & 0.79 \\
\hline $\mathrm{PaCO} 2$ at arrival $^{a}$ & $47.2(14.4)$ & $48.4(15.7)$ & 0.074 \\
\hline Length of stay ${ }^{a}$ & $10.1(6.9)$ & $9.3(7.0)$ & $<0.0001$ \\
\hline
\end{tabular}

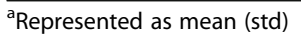

level upon ED arrival. At discharge, patients who died within 1 year were more likely to have been prescribed home oxygen therapy than those who did not die, while prescription of home mechanical ventilation support at discharge and length of stay were not different between these groups (Table 2).

In the multivariate analysis, independent variables related to one-year mortality were age, comorbidity (making reference to previous presence of cardiac, peripheral vascular or cerebral vascular diseases and dementia), admission for an eCOPD in the previous year, and $\mathrm{PaCO} 2$ at emergency department arrival, and the participant hospital. The hospital characteristics that influenced one-year mortality were the size of the hospital and whether they had a respiratory ward (Table 3).

The AUC for this model was 0.75 for the derivation cohort and 0.76 for the validation cohort (Tables 4 and 5).

A score based on the weight of the different variables included in the multivariate model was developed (Table 4). This score was stratified in 4 levels that showed a high rate of mortality at every risk level, especially in those patients having a score higher than 10 (Table 6).

\section{Discussion}

In this prospective cohort study, four groups of variables were associated with one-year mortality after an 
Table 2 Univariate analysis performed in the derivation sample $(n=1420)$

\begin{tabular}{|c|c|c|c|}
\hline & \multicolumn{3}{|l|}{ Mortality } \\
\hline & $\begin{array}{l}\text { No } \\
864 \\
\end{array}$ & $\begin{array}{l}\text { Yes } \\
495 \\
\end{array}$ & $p$-value \\
\hline $\mathrm{Age}^{\mathrm{a}}$ & $71.7(10.2)$ & $76.1(9.1)$ & $<0.0001$ \\
\hline Sex (\% male) & $763(88.3)$ & $453(91.5)$ & 0.06 \\
\hline FEV1\% & $46.6(16.3)$ & $43.2(15.4)$ & 0.004 \\
\hline FEV1\%/FVC & $53,0(12.9)$ & $51.6(14.2)$ & 0.18 \\
\hline FEV1\% categories & & & $<0.0001$ \\
\hline$\geq 80 \%$ & $24(4.5)$ & $7(2.2)$ & \\
\hline$<80->50$ & $183(34.0)$ & $85(27.3)$ & \\
\hline$<50->30$ & $144(26.8)$ & $62(19.9)$ & \\
\hline$\leq 30$ & $187(34.8)$ & $157(50.5)$ & \\
\hline Body Mass Index ${ }^{a}$ & $28.1(5.3)$ & $27.3(5.4)$ & 0.07 \\
\hline Smoking habit & & & 0.0007 \\
\hline - Never smoker & $29(3.8)$ & $19(4.7)$ & \\
\hline - Current smoker & $246(32.4)$ & $89(21.8)$ & \\
\hline - Ex-smoker & $485(63.8)$ & $300(73.5)$ & \\
\hline Cigarette pack-years $^{a}$ & $53.2(27.3)$ & $60.9(31.9)$ & 0.002 \\
\hline Charlson Comorbidity Index ${ }^{a}$ & $2.5(1.6)$ & $3.1(1.9)$ & $<0.0001$ \\
\hline $1-2$ & $536(62.0)$ & $234(47.3)$ & \\
\hline$\geq 3$ & $328(38.0)$ & $261(52.7)$ & \\
\hline Ischaemic heart disease & $111(14.0)$ & $84(18.3)$ & 0.04 \\
\hline Cardiac failure & $148(18.7)$ & $129(28.3)$ & $<0.0001$ \\
\hline Peripheral arterial disease & $113(14.4)$ & $94(20.8)$ & 0.004 \\
\hline Cerebrovascular disease & $67(8.5)$ & $72(15.9)$ & $<0.0001$ \\
\hline Cardiac-Cerebro- Peripheral vascular disease & $320(40.1)$ & $250(54.2)$ & $<0.0001$ \\
\hline Dementia & $17(2.18)$ & $31(6.84)$ & $<0.0001$ \\
\hline Diabetes mellitus & $208(25.1)$ & $129(26.9)$ & 0.46 \\
\hline Previous COPD hospitalization & $610(71.9)$ & $404(83.8)$ & $<0.0001$ \\
\hline Mean of COPD-related admissions in the previous year & $1.7(1.9)$ & $2.2(2.2)$ & 0.001 \\
\hline $\mathrm{pH}$ at arrival & $7.40(0.06)$ & $7.40(0.06)$ & 0.49 \\
\hline Acidaemia during admission & $150(18.4)$ & $84(18.1)$ & 0.89 \\
\hline $\mathrm{PaO} 2$ at arrival $^{\mathrm{a}}$ & $58.8(15.0)$ & $59.6(16.2)$ & 0.53 \\
\hline $\mathrm{PaCO} 2$ at arrival ${ }^{\mathrm{a}}$ & $46.2(13.0)$ & $48.5(15.2)$ & 0.01 \\
\hline Length of stay ${ }^{a}$ & $10.4(7.2)$ & $9.7(6.4)$ & 0.11 \\
\hline Oxygen at discharge & $329(38.1)$ & $276(55.8)$ & $<0.0001$ \\
\hline Noninvasive ventilation at discharge & $48(5.6)$ & $29(5.9)$ & 0.81 \\
\hline
\end{tabular}

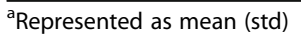

eCOPD hospitalization: general condition of the patient (older age, presence of cardiovascular, cerebrovascular, or peripheral vascular disease and dementia); clinical markers of the severity of the index event, (PaCO2 above the normal limit, at ED arrival); previous events of similar severity (hospitalization for an eCOPD in the previous year). The presence of any of these variables, added to the characteristics of the hospital where the patient was treated, were associated with higher mortality.

\section{Patient's characteristics}

Age, as a continuous variable, was an independent predictor of mortality. Age has been included, although controversially, as a variable in other multidimensional indexes for stable COPD $[9,10]$. Among patients 
Table 3 Univariate analysis. Hospital characteristics

\begin{tabular}{|c|c|c|c|}
\hline & $\begin{array}{l}\text { Dead } \\
N(\%)\end{array}$ & $\begin{array}{l}\text { Alive } \\
N(\%)\end{array}$ & $p$-value \\
\hline \multicolumn{3}{|l|}{ Hospital } & $<0.0001$ \\
\hline Total bed numbers ${ }^{a}$ & $601.0(359.3)$ & $627.3(312.0)$ & 0.005 \\
\hline \multicolumn{3}{|l|}{ Total bed numbers } & $<0.0001$ \\
\hline$-<300$ & $115(23.2)$ & $134(15.5)$ & \\
\hline$-300-599$ & $188(38.0)$ & $294(34.0)$ & \\
\hline$-\geq 600$ & $192(38.8)$ & $436(50.5)$ & \\
\hline \multicolumn{3}{|c|}{ Population served by the hospital } & 0.01 \\
\hline$-<200,000$ & $199(40.2)$ & $278(32.2)$ & \\
\hline - 200,000-299,999 & $167(33.7)$ & $338(39.1)$ & \\
\hline$-\geq 300,000$ & $129(26.1)$ & $248(28.7)$ & \\
\hline \multicolumn{3}{|l|}{ Teaching Hospital } & 0.60 \\
\hline- No & $241(48.7)$ & $407(47.1)$ & \\
\hline - Yes & $254(51.3)$ & $457(52.9)$ & \\
\hline \multicolumn{3}{|l|}{ Intensive Care Unit } & 0.17 \\
\hline$-\mathrm{No}$ & $30(6.1)$ & $38(4.4)$ & \\
\hline - Yes & 465 (93.9) & $826(95.6)$ & \\
\hline \multicolumn{3}{|l|}{ Spirometry available } & 0.47 \\
\hline$-\mathrm{No}$ & $56(11.3)$ & $87(10.1)$ & \\
\hline - Yes & $439(88.7)$ & $777(89.9)$ & \\
\hline Respiratory staff number ${ }^{a}$ & $9.43(6.2)$ & $9.49(5.8)$ & 0.44 \\
\hline \multicolumn{3}{|l|}{ Respiratory ward } & 0.04 \\
\hline$-\mathrm{No}$ & $91(18.4)$ & $123(14.2)$ & \\
\hline - Yes & $404(81.6)$ & $741(85.8)$ & \\
\hline \multicolumn{3}{|c|}{ Non-invasive ventilation available in the ward } & 0.47 \\
\hline - No & $26(5.2)$ & $38(4.4)$ & \\
\hline - Yes & $469(94.7)$ & 826 (95.6) & \\
\hline
\end{tabular}

${ }^{a}$ Represented as mean (std). $N$ frequency, \% percentage experiencing severe exacerbations, age is a key predictive factor for in-hospital mortality [11] and long-term postdischarge mortality [12]. Data from 150 hospitals in the United Kingdom indicated that age was the main predictor of 30-day mortality following hospitalization for COPD (OR, 8.5; 95\% CI, 7.7-9.4). Other predictive factors included comorbidities, and gender [13]. In other studies, age was an independent predictor of mortality during one-year of follow-up after hospitalization for an eCOPD [14, 15]. It must be noted, however, that age is a stronger predictor of long-term mortality following eCOPD hospitalization than it is as a predictor for inhospital mortality [16].

Several reasons could explain our previously mentioned results, older COPD patients tend to have a low performance status, higher level of respiratory disability, and more comorbidities. Together with a diminished awareness of the signs of an exacerbation and poorer understanding of medication [17], these factors make older patients extremely vulnerable, with generally worse outcomes and increasing 90-day mortality [17]. Moreover, respiratory specialists usually find it more difficult to control COPD in older patients than in younger ones [17]. In the UK audit, hospital care varied with age, but the lower level of care given to older patients was not associated with mortality [18]. In sum, all of these circumstances could make age a key factor contributing to mortality after hospitalization for an eCOPD.

Although comorbidities are prevalent among hospitalized eCOPD patients [19], there is some controversy over their importance as a prognostic factor for mortality. In one study, non-respiratory organ failure was most closely related to in-hospital mortality while the overall level of respiratory severity was associated with longterm mortality [16].

Table 4 Derivation cohort. Multivariate analysis. Predicting factors of mortality in 1 year

\begin{tabular}{|c|c|c|c|c|c|}
\hline & $\beta$ (s.e.) & OR $(95 \% \mathrm{Cl})$ & $p$-value & Weight & $A \cup C$ \\
\hline Intercept & $-2.12(0.56)$ & & 0.0002 & & 0.672 \\
\hline Age $^{\mathrm{b}}$ & $0.46(0.08)$ & $1.581(1.357-1.842)$ & $<0.0001$ & 2 & \\
\hline COPD related previous admissions (Yes vs. No) & $0.79(0.18)$ & $2.201(1.541-3.144)$ & $<0.0001$ & 4 & \\
\hline Cardio-cerebro-peripheral vascular disease ${ }^{a}$ (Yes vs. No) & $0.47(0.15)$ & $1.598(1.189-2.148)$ & 0.0019 & 2 & \\
\hline Dementia (Yes vs. No) & $1.09(0.39)$ & $2.973(1.394-6.340)$ & 0.0048 & 5 & \\
\hline \multicolumn{6}{|l|}{$\mathrm{PaCO} 2$} \\
\hline $45-55$ (vs. <45) & $-0.05(0.18)$ & $0.947(0.663-1.353)$ & 0.7631 & 0 & \\
\hline$>55$ (vs. < 45) & $0.47(0.19)$ & $1.601(1.102-2.326)$ & 0.0135 & 2 & \\
\hline Hospital characteristics & & & & & 0.747 \\
\hline
\end{tabular}

Hospital characteristics: defined by "total number of beds"

$\beta$ parameter estimation, s.e. standard error, $\mathrm{OR}$ odds ratio, $\mathrm{Cl}$ confidence interval, AUC area under the receiver operating characteristic Curve, Weight indicates the weight for each variable to create the risk score

${ }^{a}$ Include ischaemic heart disease, cardiac failure, peripheral vascular disease and cerebrovascular disease

${ }^{b}$ Estimation for increment of a decade with respect to patients with 50 years or less

$p$-value Hosmer y Lemeshow $=0.26$ (including in the analysis hospital $p$-value $=0.19$ ) 
Table 5 Validation cohort. Multivariate analysis. Predicting factors of COPD mortality in 1 year

\begin{tabular}{llll}
\hline & $\beta$ (s.e.) & OR (95\% Cl) & $p$-value \\
\hline Intercept & $-3.08(0.55)$ & $<0.0001$ & 0.672 \\
Age $^{\text {b }}$ & $0.43(0.06)$ & $1.530(1.367-1.712)$ & $<0.0001$ \\
COPD related previous admissions (Yes vs. No) & $0.72(0.11)$ & $2.045(1.640-2.550)$ & $<0.0001$ \\
Cardio-cerebro-peripheral vascular disease (Yes vs. No) & $0.31(0.11)$ & $1.367(1.097-1.705)$ & 0.0054 \\
Dementia (Yes vs. No) & $0.50(0.26)$ & $1.648(0.984-2.758)$ & 0.0575 \\
PaCO2 & & & 0.0917 \\
$45-55$ (vs. $<45)$ & $0.22(0.13)$ & $1.245(0.965-1.607)$ & 0.0001 \\
$>55$ (vs. $<45)$ & $0.51(0.13)$ & $1.665(1.280-2.165)$ & 0.763 \\
Hospital characteristics & & &
\end{tabular}

Hospital characteristics: defined by "total number of beds"

$\beta$ parameter estimation, s.e. standard error, OR odds ratio, $C l$ confidence interval, AUC area under the receiver operating characteristic curve

anclude ischaemic heart disease, cardiac failure, peripheral arterial disease and cerebrovascular disease

${ }^{\mathrm{b}}$ Estimation for increment of a decade. With respect to patients with 50 years or less

$p$-value Hosmer y Lemeshow $=0.25$ (including in the analysis hospital $p$-value $=0,37$ )

In another study comorbidities-cor pulmonale, left ventricular failure, neurological conditions, and nonrespiratory malignancies-were associated with in-hospital mortality while 90 -day mortality was also increased by the presence of lung cancer or arrhythmias [19]. Almagro et al. showed that the Charlson Comorbidity Index score were associated with 90-day mortality [20]. Comorbidities such as cardiac failure [21], ischaemic heart disease [22], stroke, and diabetes [23] have also been identified as predictors of mortality after hospitalization for an eCOPD.

We did not observe an association between comorbidities evaluated by the Charlson index and mortality during the one-year follow-up, as in another study was [24]. In contrast, in our cohort specific comorbidities-cardiac disease (ischaemic heart disease, chronic heart failure), cerebrovascular disease, and peripheral vascular disease-were independently related to mortality. It seems that the impact of the different comorbidities is variable with respect to the outcome analysed [25] and is focused on the cardiocerebro-vascular comorbidities, because not all the comorbidities have the same importance.

Apart from the cardio-cerebro-vascular comorbidities, it is worth mentioning dementia as a variable associated to mortality in our study. Prevalence of cognitive dysfunction is very variable in COPD patients, (up to 61\%), depending on the place where the study was carried out [26].

COPD patients are prone to being affected by deterioration of their level of cognitive function, and there are several mechanisms involved, from the hypoxaemia, usually present in COPD, to smoking and some concurrent comorbidities, as cardiovascular [27].

Cognitive deterioration has been shown to have a great impact on important outcomes. In patients admitted to a general hospital those with dementia had a mortality rate of $48 \%$ after 1 year, higher than that of patients without dementia [28]. In COPD, those patients admitted suffering dementia had 38\% and 69\% higher risk of severe sepsis and hospital mortality respectively [29].

Our study adds that in COPD patients, dementia was a key point and the strongest variable associated to mortality in the mid term, after one hospitalization.

In sum, what our study showed was the important relationship between comorbidities and mortality, but not comorbidities in general, but some specific comorbidities such as cardio-cerebro-vascular and dementia.

\section{Factors of the index event (hospitalization)}

Several variables were registered from the hospitalization, however our study showed that only hypercapnia at the

Table 6 Description of the mortality rate at 1 year in the different risk groups

\begin{tabular}{|c|c|c|c|c|c|c|}
\hline & \multicolumn{3}{|c|}{ Derivation sample } & \multicolumn{3}{|c|}{ Validation sample } \\
\hline & $\bar{N}(\%)$ & Mortality 1 year & $p$-value & $N(\%)$ & Mortality 1 year & $p$-value \\
\hline Risk groups & & & $<0.0001$ & & & $<0.0001$ \\
\hline Low (0-5) & $83(8.03)$ & $7(8.43)$ & & 498 (15.39) & $17(3.41)$ & \\
\hline Low-Medium (6-7) & $112(10.83)$ & $22(19.64)$ & & $513(15.86)$ & $38(7.41)$ & \\
\hline Medium-High (8-10) & $412(39.85)$ & $134(32.52)$ & & $1307(40.40)$ & 201 (15.38) & \\
\hline High $(>10)$ & $427(41.30)$ & $206(48.24)$ & & 917 (28.35) & $236(25.74)$ & \\
\hline AUC (95\% Cl) & \multicolumn{3}{|c|}{$0.740(0.709-0.771)$} & \multicolumn{2}{|c|}{$0.763(0.741-0.784)$} & \\
\hline
\end{tabular}

$\mathrm{N}$ frequency, \% percentage, $\mathrm{Cl}$ confidence Interval 
time of hospital admission was associated with one-year mortality.

$\mathrm{PaCO} 2$ has been recognized as a key predictor of inhospital mortality [30] and one-year after admission mortality [14, 22] among eCOPD patients. A study that included COPD patients admitted to the intensive care unit established that the severity of the exacerbation reflected by respiratory physiology influenced one-year mortality but not in-hospital mortality [16]. Patients admitted with a $\mathrm{PaCO} 2>50 \mathrm{mmHg}$ - which would indicate the severity of the underlying respiratory disease, like ventilation/ perfusion mismatch or hypoventilation-had higher one-year mortality than those with $\mathrm{PaCO} 2<$ $50 \mathrm{mmHg}$. It is possible that in this study, the homogeneity of the cohort (ICU patients only) could have diluted the discriminative capacity of the analysis, limiting the possibility of finding any relationship between in-hospital mortality and variables (like $\mathrm{PaCO} 2$ ) that reflect the physiological respiratory impairment during an eCOPD.

We were not able to demonstrate if hypercapnia persisted at discharge, and if its persistence was related to mortality, as has been suggested by others [20]. Neither did we have any information on patient $\mathrm{PaCO} 2$ in a stable condition of our cohorts.

\section{Previous hospitalizations}

Previous eCOPD hospitalizations have been identified as an independent predictor of mortality in cohorts of stable and hospitalized patients. Soler-Cataluña et al., for example, demonstrated that mortality increases with the frequency of severe exacerbations requiring hospital evaluation [31]. Other researchers have observed that the number of severe eCOPD requiring hospitalization increases the risk of respiratory and all-cause mortality regardless of factors such as age, $\mathrm{FEV}_{1}$, dyspnoea, cumulative pack-year smoking history, and health-related quality of life [32].

Across the lifespan of COPD patients, the addition of every new hospitalization significantly increases the rate of mortality, and the risk of other severe eCOPD peaks during the 3 months after the index event [1].

In cohorts derived from databases, episodes of previous COPD-related hospitalizations were an independent predictor of mortality [21, 33]. In fact, previous hospitalizations and comorbidities have been included as components of a multidimensional score predicting mortality in a cohort of hospitalized patients.

In our study having had one hospitalization the year before the index-event increased the probability of mortality the year after by $60 \%$, which would be in accordance with the results of studies previously mentioned and outline more precisely the profile of the patient that should be carefully monitored after and eCOPD hospitalization.

\section{Hospital characteristics}

Hospital characteristics were reported as a predictor of mortality in the UK national audit 2003. Inpatient and 90-day mortality were lower in hospitals with more respiratory staff per 1000 beds. No other associations were found between other hospital resources and mortality.

The European COPD audit team evaluated adherence to 10 key management recommendations set forth by the GOLD standards in 13 European countries. It found great variability between hospitals and across countries, especially connected with the availability of the level of severity of the obstruction and the use of oxygen and non-invasive ventilation. The audit also showed that larger hospitals have more resources but this does not imply a better quality of care.

Walker et al. showed that 30-day mortality after hospitalization for an eCOPD was quite variable from 1 year to the following across various hospitals. Mortality in that period was independent of hospital size and of whether a respiratory specialist was responsible for the discharge of the patient [13].

In our study, hospital size, as measured by bed numbers and population served, was related to one-year mortality. Knowing the potential limitation of using data from one brief time point rather than data collected over several years we could speculate that having more resources provided not only better treatment of the index episode but better follow-up care afterward. We observed a significant influence of the hospital on one-year mortality since the AUC increases from 0.68 to 0.77 after including the variable hospital in the analysis. Nevertheless, we were not able to establish whether this is due exclusively to the hospital, or is also due to the primary care organization, the regional medical or social characteristics involved in the care of these patients, or all of these together. In any case including hospital size seems to be an important point in the final results.

\section{Strengths and limitations}

Strengths of our study included are the number of patients we were able to follow, the length of follow-up, and the fact that patients were recruited from multiple centres. The usage of multilevel models provides a better approach than ordinary logistic regression models when patients are clustered in different groups, as in our case, that we have patients clustered in different hospitals. In this way, the correlation effect among patients from the same hospitals is controlled, as we do not consider them independently.

Several limitations must also be noted, primarily related to the design of the study as an audit of care in eCOPD, which implies missing data. We used for the analysis only those variables with less than $15 \%$ of 
missing data. Another limitation is that we were not able to recover the whole cohort of the Spanish audit. Instead, we analysed only those hospitals that conducted a follow-up of 1 year. We checked our sample against the whole cohort and verified that there were no differences in the clinical characteristics of the patients. Patients who died during the admission were not included in this analysis, only discharged patients. We were not able to pinpoint the cause of death because it is not accurately registered in death records, but this was not the objective of this study. As an audit of general practice some variables currently used as part of predictive mortality scores were not collected. Thus, a comparison with others mortality scores was not possible. The low percentage of women in both cohorts of the study limited the possibility of carrying out an analysis about potential differences with respect to men in the main outcomes studied.

\section{Conclusions}

In a cohort of patients hospitalized for an eCOPD, predictors of mortality in the year following the index hospitalization were patient characteristic age, characteristics of the disease (admission for an eCOPD in the previous year and specific comorbidities), aspects of the index event (PaCO2), and the characteristics of the hospitals in which the patients were treated. Some of these aspect are potentially adjustable to impact in the care and outcomes of severe eCOPD.

In conclusion our study provides the patient profile with the highest probability of mortality during the year after an eCOPD hospitalization. We should pay attention to a man in his seventies, with cardio-vascular and/or dementia, with a previous eCOPD hospitalization the year before the index event and with hypercapnia $>50 \mathrm{mmHg}$ during the admission. In those patients with these characteristics a more personalized follow-up is mandatory.

\section{Abbreviations \\ AUC: Area under the receiver-operating curve; COPD: Chronic obstructive pulmonary disease; eCOPD: Exacerbation of COPD; ED: Emergency department}

\section{Acknowledgements}

We are grateful for the support of the participating hospitals. Grupo AUDIPOC España-CEPA Subproyecto 1 COMITÉ COORDINADOR: ESTEBAN, Cristóbal. Neumología, Hospital de Galdakao. Vizcaya. POZO RODRIGUEZ, Francisco. Neumología, Hospital 12 de Octubre. Madrid. CASTRO ACOSTA, Ady Angélica. Médico Investigador CIBERES Unidad de Epidemiología Clínica, Hospital Universitario 12 de octubre. Madrid. BOUKICHOU ABDELKADER, Nisa Lic. CC y TT. Estadísticas. Investigador CIBERES Unidad de Epidemiología Clínica, Hospital Universitario 12 de octubre. Madrid. ESTEBAN GARCIA-NAVAS, Sara Investigador CIBERES Unidad de Epidemiología Clínica, Hospital Universitario 12 de octubre. Madrid. COMITÉ CIENTíFICO: POZO RODRÍGUEZ, Francisco. AGUSTÍ, Alvar. Neumología, Instituto Cardiotorácico Hospital Clinic, Barcelona. ÁLVAREZ MARTínEZ, Carlos José. Neumología, Hospital 12 de Octubre. Madrid. CAPELASTEGUI SAIZ, Alberto. Neumología, Barakaldo. Bilbao. HERNÁNDEZ CARCERENY, Carme. Neumología, Hospital Clinic. Barcelona. IZQUIERDO
ALONSO, José Luis. Neumología, Hospital de Guadalajara. LOPEZ CAMPOS, José Luís. Neumología, Hospital Universitario Virgen del Rocío. Sevilla. MELERO MORENO, Carlos. Neumología, Hospital Universitario 12 de octubre. Madrid. ANDALUCIA: RESPONSABLE REGIONAL: José Luís López Campos. Neumología, Hospital Universitario Virgen del Rocío. RESPONSABLES LOCALES: Almería, Complejo Hospitalario Torrecárdenas: José Calvo Bonachera. Cádiz, Hospital de La Línea de la Concepción: Armando Falces Sierra, Hospital General de Jerez de la Frontera: Gregorio Soto Campos, Hospital Puerta del Mar: Fernando Romero Valero y Isidro Blasco, Hospital Puerto Real: Jesús Sánchez Gómez. Hospital Universitario Reina Sofía: Marisol Arenas de la Riva y María Jesús Cobos Ceballos. Granada: Hospital Universitario San Cecilio: Alicia Conde Valero. Huelva: Hospital Infanta Elena: Rosa Vázquez Oliva y Fernando Hernández Utrera. Hospital Juan Ramón Jiménez: Rut Ayerbe García. Jaén: Centro Hospitalario Ciudad de Jaén: Bernardino Alcázar Navarrete. E.P.H.A.G. Alto Guadalquivir (Andujar): Juan Manuel Bravo Santervás. Málaga: Hospital Costa del Sol: José Fernández Guerra. Hospital Comarcal de Vélez Málaga: Carlos Rueda, Hospital Regional Carlos Haya: José Luís de la Cruz Ríos. Hospital Serranía de Ronda: Francisco José Cabello Rueda. Hospital Virgen de la Victoria: Francisco Marín Sánchez. Sevilla: Hospital de la Merced - Osuna: José Pérez Ronchel. Hospital Universitario Virgen del Rocío: José Luís López Campos. Hospital Universitario Valme: Inmaculada Alfageme Michavila. ARAGÓN: RESPONSABLE REGIONAL: Luis Borderías. Neumología, Hospital San Jorge de Huesca, José Manuel Gascón Pelegrín. Neumología, Hospital Miguel Servert. Zaragoza, Instituto Aragonés de Salud: Anselmo López y Mónica Torrijos RESPONSABLES LOCALES: Hospital Clínico Universitario Lozano Bleza: Joaquín Carlos Costan Galicia. Hospital Miguel Servert: Salvador Bello Dronda, Andrés Sánchez Barón y José Manuel Gascón Pelegrín. Hospital San Jorge de Huesca: Luis Borderías. CANARIAS: RESPONSABLE REGIONAL Ana Velázquez Benítez. H Ntra Señora de la Candelaria. José Gabriel Julia. Neumología, Hospital Dr. Negrín RESPONSABLES LOCALES: Las Palmas: Hospital Dr. Negrín: Carlos Cabrera López. Lanzarote: Hospital Dr. José Molina Orosa, Lanzarote: Javier Navarro Esteva. Santa Cruz de Tenerife: HM Nuestra Señora de Candelaria: Magdalena Alonso, Ruth Pitti, José Batista y Orlando Acosta Fernández. Hospital Universitario de Tenerife: José Antonio Gullón. CANTABRIA: RESPONSABLE REGIONAL Ramón Agüero Balbín. Neumología, Hospital Marqués de Valdecilla. Cantabria: Hospital de Laredo: Miguel Zabaleta Murguiondo. Hospital Marqués de Valdecilla: Beatriz Abascal Bolado y Ramón Agüero Balbín. Hospital Sierrallana: Mar García Pérez. CASTILLA LA MANCHA: RESPONSABLE REGIONAL Jose Celdran Gil. Neumología, Hospital Nuestra Señora del Prado de Talavera. Jesús Fernández Francés. Neumología, Hospital de Guadalajara. RESPONSABLES LOCALES: Albacete: Hospital de Albacete: Ana Isabel Tornero. Ciudad Real: Hospital La Mancha Centro (ALCAZAR): Gloria Francisco. Hospital Manzanares. Fernando Pedraza y Marisi Verdugo. Cuenca: Hospital Virgen de la Luz de Cuenca: María José Peirón. Guadalajara: Hospital de Guadalajara: Jesús Fernández Francés y JL Izquierdo. Soria: Complejo Asistencial de Soria, H Santa Bárbara: José Luis Orcastegui Candial Toledo: Hospital Nuestra Señora del Prado de Talavera: José Celdrán. Hospital Virgen de la Luz de Toledo: Encarnación López Gabaldón. CASTILLA Y LEÓN: RESPONSABLE REGIONAL Jesús Reyes Hernández Hernández. Neumología, Hospital Nuestra señora de Sonsoles. RESPONSABLES LOCALES: Ávila: H Nuestra señora de Sonsoles: José Eugenio Alonso Muñoz y Eugenio Trujillo Santos. Burgos: Complejo Hospitalario de Burgos: Luís Rodríguez Pascual. Hospital Santiago Apóstol de Miranda de Ebro: Esteban Pascual Pablo. Hospital Santos Reyes Aranda de Duero: Pedro Cancelo Suárez. León: Complejo Asistencial de León: Ana José Seco García. Hospital del Bierzo: Juan Ortiz De Saracho y Bobo. Palencia: Complejo Asistencial de Palencia: María Ángeles Fernández Jorge. Salamanca: Complejo hospitalario de Salamanca: Rosa Cordovilla Pérez. Segovia: Hospital General de Segovia: Graciliano Estrada Trigueras. Soria: Complejo Asistencial de Soria, Hospital Santa Bárbara: José Luís Orcastegui Candial. Valladolid: Hospital Clínico Universitario: Carlos Disdier y Enrique Macías Fernández. Hospital Río Hortera: Félix del Campo Matías. Zamora: Complejo Hospitalario de Zamora. Hospital de Benavente: Carmen Fernández García, Cecilia Alonso Medievilla y María Victoria Domínguez Rodríguez. CATALUÑA: RESPONSABLE REGIONAL Carlos Martínez Rivera. Neumología, Hospital Universitari Germans Trias i Pujol. Eduard Monsó Molas. Neumología, Hospital Universitari Germans Trias i Pujol. RESPONSABLES LOCALES: Barcelona: Hospital Clinic Barcelona: Néstor Soler Porcar, Carmen Hernández. Hospital Comarcal de L'alt Penedés,Vilefrance de Penedés: Nuria Rodríguez Lázaro. Hospital del Mar: Joaquim Gea, Roser Pedreny y Sergi Pascual. Hospital General de Vic: Fernando Ruiz Mori. Hospital San Pau: Antonio Antón y 
Virginia Pajares Ruiz. Virginia Pajares Ruiz. Hospital Universitari Germans Trias i Pujol: Eduard Monsó Molas y Ignasi Garcia Olivé. Hospital Vall d’Hebron: Esther Rodríguez González, Eva Lozano, Eva Tapia Melechon, Ma Angeles Barrio, Ma Antonia Roman, Mieria Guzman Perez, Milagros Gandara Sanz y Xavier Pérez. Hospital Viladecans: Joan Anton Lloret Queraltó, Mercedes Palau Benavent y Nuria Celorrio Jiménez. Gerona (Girona): Hospital Universitario Doctor Josep Trueta: Manuel Haro Estarriol. Lérida (Lleida): Hospital Arnau: Ferrán Barbé. H General Par Sanitari Sant Joan de Déu: Luis Lores Obradors, H Parc Taulí de Sabadell: Eduard Monso, H Joan XXIII de Tarragona: Leonardo Esteban MADRID RESPONSABLE REGIONAL. Julio Ancoechea Bermúdez. Neumología, Hospital de la Princesa. Carlos Melero Moreno y Carlos José Álvarez Martínez. Neumología, Hospital Universitario 12 de Octubre. RESPONSABLES LOCALES: Madrid. H. 12 OCTUBRE: Virginia Pérez González. Hospital Clínico San Carlos: Gema Rodríguez Trigo. Hospital de la Princesa: Enrique Zamora García. Hospital de Tajo, Aranjuez: José. Fernando González Torralba. Hospital de Valdemoro: Rocío García García. Hospital El Escorial: Francisco Gómez Rico. Hospital Fundación Alcorcón: Barbara Steen. Eva De Higes Martínez. Mercedes Izquierdo Patrón y Ángela Ramos Pinedo. Hospital Gómez Ulla: Javier Jareño, Ignacio Granda Uribe y Sergio Campos Tellez. Hospital Gregorio Marañón: Jorge García, José De Miguel Rodríguez González Moro. Hospital Infanta Cristina, Parla: Beatriz Jara Chinarro, María Teresa Rio. Ramírez. Hospital Infanta Sofía: Raúl Moreno Zabaleta, Maria Teresa Ramirez Prieto y Blas Rojo Moreno Arrones. Hospital La Paz: Francisco García Río y Sergio Alcolea Batres. Hospital Puerta de Hierro: Rosa Malo de Molina Ruíz, Antolin López Viña y Pietat Ussetti. Hospital Ramón y Cajal: Esteban Pérez Rodríguez y Salvador Díaz Lobato. Hospital Infanta Leonor: Carmen Matesanz Ruíz, Maria Jesus Buendia. Hospital Sureste Arganda del Rey: Sergio Salgado Aranda. Fundación Jiménez Díaz: German Peces Barba. Hospital de Getafe: Ma Antonia Juretschke Moragues. Hospital Príncipe de Asturias Alcalá Henares: Soledad Alonso Viteri. Hospital de Móstoles: Dolores Álvaro. Hospital Severo Ochoa de Leganés: Asunción Perpina. Hospital del Henares: Ma Ángeles Ruíz-Cobos. C.F.NAVARRA: RESPONSABLE REGIONAL. Javier Hueto Perez de Heredia. Neumología, Complejo Hospitalario de Navarra. RESPONSABLES LOCALES: Navarra: Complejo hospitalario de Navarra: José Javier Lorza Blasco, José Antonio Cascante Rodrigo, Jalil Abú-Shams, Victor Manuel Eguía Astibia, Idoya Pascal Martínez, Joan Boldú Mitgans y Pilar Cebollero Rivas. Hospital García Orcoyen De Estella: Idoya Pascal Martínez. Hospital Reina Sofía De Tudela: José Antonio Cascante Rodrigo y José Javier Lorza Blasco. Hospital Virgen Del Camino De Pamplona: C. VALENCIANA: RESPONSABLE REGIONAL Pablo Catalán Serra y Juan José Soler Cataluña. Neumología, Hospital de Requena. RESPONSABLES LOCALES: Alicante: Hospital de Elda: Alejandro Muñoz. Hospital de Orihuela: José Manuel Querol. Hospital de San Joan: Eusebi Chiner Vives y Adaluz Andreu Rodríguez. Hospital de Torrevieja: Esther Pastor. Castellón de la Plana: Hospital de la Magdalena: Khaled Bdeir Egnayem Hospital de La Plana: Luis Miravet. Hospital General de Castellón: Margarita Marín Royo. Valencia: Hospital Clínico Valencia: María Cruz González Villaescusa. Hospital de Requena: Pablo Catalán Serra y Juan José Soler Cataluña. Hospital Dr. Peset: Estrella Fernández Fabrellas, Ángela Cervera Juan, Alberto Herreron Silvestre y Alfonso Martinez Martinez. Hospital Francés de Borja, Gandia: Concha Pellicer Ciscar. Hospital de la Rivera: Elsa Naval Sendra. Hospital Sagunto: Eva Martínez Moragon. Hospital Universitario la Fe: Montserrat Leon Fabregas. EXTREMADURA: RESPONSABLE REGIONAL Juan Antonio Riesco Miranda. Neumología, Hospital de Cáceres. RESPONSABLES LOCALES: Badajoz: Hospital Infanta Cristina de Badajoz: José Antonio Gutierrez Lara, Fernando Fuentes. Cáceres: Hospital de Cáceres: Juan Antonio Riesco Miranda. Hospital de Plasencia: Miguel Ángel Hernández Mezquita. Mérida: Hospital de Mérida: Germán García Vinuesa. GALICIA: RESPONSABLE REGIONAL Alberto Fernández Villar. Neumología, Complejo hospitalario de Vigo. Juan Suárez Antelo. Neumología, Complejo Hospitalario Universitario A Coruña. RESPONSABLES LOCALES: La Coruña (A Coruña): Complejo Hospitalario Universitario A Coruña: Juan Suarez Antelo. FPH Barbanza: Emilio Manuel Padin Paz. Hospital de Conxo - Santiago de Compostela: Jesús Suarez Martinez. Lugo: Hospital Comarcal Burela: Sonia Paredes Vila. Hospital Xeral, Lugo: Rafael Golpe Gomez y Luis Pérez de Llano. Orense (Ourense): CH Ourense: Pedro Marcos, Carlos Vilariño Pombo y Jose Manuel García Pazos. Pontevedra: Hospital provincial de Pontevedra: Adolfo Baloira. Hospital Xeral, Vigo: Alberto Fernández Villar y Cristina Represas Represas. Hospital do Meixoero, Vigo: Manuel Nuñez Delgado. Hospital Povisa: Maria Dolores Corbacho Abelaira. Hospital Xeral, Vigo: Marta Nuñez Fernandez. ISLAS BALEARES: RESPONSABLE REGIONAL Borja García Cosio. Neumología, Hospital Son Espases. RESPONSABLES LOCALES: Palma de Mallorca: Hospital Comarcal de Inca: Elena Laserna Martinez. Hospital de Manacor: Rosa Maria Irigaray
Canals. Hospital de San Llatzer: Salvador Pons Vivas. Hospital Son Espases: Borja Garcia Cosio. Menorca: Hospital Mateu Orfila: Jordi Guerrero. Ibiza: Hospital Can Misses, Ibiza: Alvaro De Astorza y Antonio Cascales García. LA RIOJA: RESPONSABLE REGIONAL Manuel Barrón Medrano. Neumología, Hospital de la Rioja. RESPONSABLES LOCALES: La Rioja: Fundación Hospital de Calahorra: Susana Chic Palacin y Manuel Barron Medrano. Hospital De La Rioja: Carlos Ruiz Martínez y Manuel Barron Medrano. PAIS VASCO: RESPONSABLE REGIONAL Cristóbal Esteban. Neumología, Hospital de Galdakao. RESPONSABLES LOCALES: Álava: H de Santiago: Ma Ines Carrascosa. H Txagorritxu: Laura Tomas. Gipuzcoa (Guipuzkoa): H Bidasoa: Jose Antonio Miguel Arce, Ma Asunción Celaya y Silvia Dorronsoro. H Donostia: Ma Rosa Berdejo, Mónica Rayón y Gabriel Zubillaga Garmendia. Hospital de Mendaro: Jose Ignacion Royo, Susana Chic Palacin y Nicolás Gurrutxaga. H de Mondragón: Iñaki Peña y Mikel Temprano Gogenola. H Zumarraga: Silvia Dorronsoro, Cristina Estirado y Raquel Sanchez. Vizcaya (Bizkaia): H Basurto: Miren Begoña Salinas y lgor Iturbe. H Cruces: José Ma Antoñana y Pilar Marin. H Galdakao: Cristóbal Esteban, Mikel Egurrola y Alberto Capelastegui. H San Eloy: Juan Manuel Nuñez, Jesús Caminos y Luis Alberto Ruiz Iturriaga. PRINCIPADO DE ASTURIAS RESPONSABLE REGIONAL Cristina Martinez. Neumología, Hospital Universitario Central de Asturias. RESPONSABLES LOCALES: Hospital Universitario Central de Asturias: Marta García Clemente, Hospital de Cabueñes Gijón: Teresa Pascual Pascual y Concepción Diaz Sanchez. Hospital del Oriente-Arriondas: Blanca Requejo Mañana. Hospital Fundación Jove: Benigno Del Busto Lorenzo. Hospital San Agustín, Avilés: Fernando Álvarez Navascues y Marta García Clemente. Hospital Universitario Central de Asturias: Aida Quero Martínez y Cristina Martínez. Hospital Valle del Nalón Langreo: Hortencia Canto Argiz. REGION DE MURCIA: RESPONSABLE REGIONAL. Juan Miguel Sánchez Nieto. Neumología, Hospital General Universitario Morales Meseguer. RESPONSABLES LOCALES: Hospital de los Arcos: Damián Melia Alvarado, Jose A Ros Lucas y Nuria Castejon Piña. Hospital General Universitario Morales Meseguer: Roberto Bernabeu Mora, Juan Miguel Sanchez Nieto y Maria Loreto Alemany Frances. Hospital Universitario Santa Lucía: Ines Bernal Belijar, Jose Javier Martinez Garceran, Mercedes Guillamon Sanchez y Pilar Berlinches Acin. Hospital U Reina Sofía: Carlos Orts Arqueros, Maria Jesus Aviles Ingles y Pedro Mendez Martinez.

\section{Funding}

This work was supported in part by grants from the Fondo de Investigación Sanitaria PI 06\10.

\section{Availability of data and materials}

The datasets used and/or analyzed during the current study are available from the corresponding author on reasonable request.

\section{Authors' contributions}

Conception and design: FPR; Analysis and interpretation: CE, ACA, FPR; Drafting the manuscript for important intellectual content: CE, ACA, CJAM, AC, JLLP, FPR. All authors have read and approved the final version of this manuscript.

\section{Ethics approval and consent to participate}

The study was approved by Instituto de Salud Carlos III CEI PI 30_2011-v4 and by the Ethics Committees of every hospital involved in the study. All participants provided written informed consent.

\section{Consent for publication}

Not applicable

\section{Competing interests}

The authors declare that they have no competing interests.

\section{Publisher's Note}

Springer Nature remains neutral with regard to jurisdictional claims in published maps and institutional affiliations.

\section{Author details}

${ }^{1}$ Pulmonary Service, Galdakao-Usansolo Hospital, Galdakao, Bizkaia, Spain. ${ }^{2}$ Pulmonary Service and Research Institute, Doce de Octubre University Hospital, Madrid, Spain. ${ }^{3}$ CIBER Enfermedades Respiratorias (CIBERES), Madrid, Spain. ${ }^{4}$ Hospital Universitario Virgen del Rocío, Medical- Surgical Unit of Respiratory Diseases, Seville, Spain. ${ }^{5}$ Network and Health Services Research Chronic Diseases (REDISSEC), Bilbao, Bizkaia, Spain. 
Received: 3 August 2017 Accepted: 4 January 2018

Published online: 25 January 2018

\section{References}

1. Suissa S, Dell'Aniello S, Ernst P. Long-term natural history of chronic obstructive pulmonary disease: severe exacerbations and mortality. Thorax. 2012:67:957-63.

2. Steer J, Gibson GJ, Bourke SC. Predicting outcomes following hospitalization for acute exacerbations of COPD. QJM. 2010;103:817-29.

3. Singanayagam A, Schembri S, Chalmers JD. Predictors of mortality in hospitalized adults with acute exacerbation of chronic obstructive pulmonary disease. Ann Am Thorac Soc. 2013;10:81-9.

4. Celli BC, Cote CG, Marín JM, Casanova C, Montes de Oca M, Mendez RA, Pinto Plata V, Cabral HJ. The body-mass index, airflow obstruction, dyspnea, and exercise capacity index in chronic obstructive pulmonary disease. NEJM. 2004;350:1005-12.

5. Puhan MA, Garcia-Aymerich J, Frey M, ter Riet G, Antó JM, Agustí AG, Gómez FP, Rodríguez-Roisín R, Moons KG, Kessels AG, Held U. Expansion of the prognostic assessment of patients with chronic obstructive pulmonary disease: the updated BODE index and the ADO index. Lancet. 2009:374:704-11.

6. Pozo-Rodríguez F, Alvarez CJ, Castro-Acosta A, Melero Moreno C, Capelastegui A, Esteban C, Hernández Carcereny C, López-Campos JL, Izquierdo Alonso JL, López Quílez A, Agustí A, por el Grupo AUDIPOC España. Clinical audit of patients admitted to hospital in Spain due to exacerbation of COPD (AUDIPOC study): method and organisation. Arch Bronconeumol. 2010;46:349-57.

7. Lopez-Campos JL, Hartl S, Pozo-Rodriguez F, et al. European COPD Audit: design, organisation of work and methodology. Eur Respir J. 2013;41:270-6.

8. Puhan MA, Hansel NN, Sobradillo $P$, Enright $P$, Lange $P$, Hickson D, Menezes AM, Riet GT, Held U, Domingo-Salvany A, Mosenifar Z, Antó JM, Moons KG, Kessels A, Garcia-Aymerich J, International COPD Cohorts Collaboration Working Group. Large-scale international validation of the ADO index in subjects with COPD: an individual subject data analysis of 10 cohorts. BMJ Open. 2012;2:e002152.

9. Esteban C, Quintana JM, Aburto M, Moraza J, Arostegui I, España PP, Aizpir S, Capelastegui A. The health, activity, dyspnea, obstruction, age, and hospitalization: prognostic score for stable COPD patients. Respir Med. 2011; 105:1662-70.

10. Patil SP, Krishnan JA, Lechtzin N, Diette GB. In-hospital mortality following acute exacerbations of chronic obstructive pulmonary disease. Arch Intern Med. 2003;163:1180-6.

11. Piquet J, Chavaillon JM, David P, Martin F, Blanchon F, Roche N, French College of General Hospital Respiratory Physicians (CPHG). High-risk patients following hospitalisation for an acute exacerbation of COPD. Eur Respir J. 2013:42:946-55.

12. Walker PP, Thompson E, Crone H, Flatt G, Holton K, Hill SL, Pearson MG. Use of mortality within 30 days of a COPD hospitalisation as a measure of COPD care in UK hospitals. Thorax. 2013;68:968-70.

13. Groenewegen KH, Schols AM, Wouters EF. Mortality and mortalityrelated factors after hospitalization for acute exacerbation of COPD. Chest. 2003;124:459-67.

14. Connors AF Jr, Dawson NV, Thomas C, Harrell FE Jr, Desbiens N, Fulkerson WJ, Kussin P, Bellamy P, Goldman L, Knaus WA. Outcomes following acute exacerbation of severe chronic obstructive lung disease. The SUPPORT investigators (Study to Understand Prognoses and Preferences for Outcomes and Risks of Treatments). Am J Respir Crit Care Med. 1996;154:959-67.

15. Seneff MG, Wagner DP, Wagner RP, Zimmerman JE, Knaus WA. Hospital and 1-year survival of patients admitted to intensive care units with acute exacerbation of chronic obstructive pulmonary disease. JAMA. 1995;274:1852-7.

16. Stone RA, Lowe D, Potter JM, Buckingham RJ, Roberts CM, Pursey NJ. Managing patients with COPD exacerbation: does age matter? Age Ageing. 2012:41:461-8.

17. Connolly MJ, Lowe D, Anstey K, Hosker HS, Pearson MG, Roberts CM, Society BT, the Royal College of Physicians Clinical Effectiveness Evaluation Unit (CEEu). Admissions to hospital with exacerbations of chronic obstructive pulmonary disease: Effect of age related factors and service organisation. Thorax. 2006;61:843-8.
18. Roberts CM, Stone RA, Lowe D, Pursey NA, Buckingham RJ. Co-morbidities and 90-day outcomes in hospitalized COPD exacerbations. COPD. 2011;8:354-61.

19. Almagro $P$, Calbo E, Ochoa de Echagüen A, Barreiro B, Quintana S, Heredia JL, Garau J. Mortality after hospitalization for COPD. Chest. 2002;121:1441-8.

20. McGhan R, Radcliff $T$, Fish R, Sutherland ER, Welsh C, Make B. Predictors of rehospitalization and death after a severe exacerbation of COPD. Chest. 2007:132:1748-55

21. Fruchter $\mathrm{O}$, Yigla M. Predictors of long-term survival in elderly patients hospitalized for acute exacerbations of chronic obstructive pulmonary disease. Respirology. 2008;13:851-5.

22. Gudmundsson G, Ulrik CS, Gislason T, Lindberg E, Brøndum E, Bakke P, Janson C. Long-term survival in patients hospitalized for chronic obstructive pulmonary disease: a prospective observational study in the Nordic countries. Int J Chron Obstruct Pulmon Dis. 2012;7:571-6.

23. Ranieri P, Bianchetti A, Margiotta A, Virgillo A, Clini EM, Trabucchi M. Predictors of 6-month mortality in elderly patients with mild chronic obstructive pulmonary disease discharged from a medical ward after acute nonacidotic exacerbation. J Am Geriatr Soc. 2008;56:909-13.

24. Cheng $Y$, Han X, Luo $Y, X u$ W. Deaths of obstructive lung disease in the Yangpu district of Shanghai from 2003 through 2011: a multiple cause analysis. Chin Med J. 2014;127:1619-25.

25. Steer J, Gibson J, Bourke SC. The DECAF Score: predicting hospital mortality in exacerbations of chronic obstructive pulmonary disease. Thorax. 2012;67:970-6.

26. Gunen H, Hacievliyagil SS, Kosar F, Mutlu LC, Gulbas G, Pehlivan E, Sahin I, Kizkin O. Factors affecting survival of hospitalised patients with COPD. Eur Respir J. 2005;26:234-41.

27. Soler-Cataluña JJ, Martinez-Garcia MA, Román Sánchez P, et al. Severe acute exacerbations and mortality in patients with chronic obstructive pulmonary disease. Thorax. 2005;60:925-31.

28. Esteban C, Quintana JM, Aburto M, Moraza J, Egurrola M, España PP Pérez-Izquierdo J, Capelastegui A. Predictors of mortality in patients with stable COPD. J Gen Intern Med. 2008;23:1829-34.

29. Slenter RH, Sprooten RT, Kotz D, Wesseling G, Wouters EF, Rohde GG. Predictors of 1-year mortality at hospital admission for acute exacerbations of chronic obstructive pulmonary disease. Respiration. 2013;85:15-26.

30. Almagro P, Soriano J, Cabrera F, Boixeda R, Alonso M, Barreiro B, Diez-Manglano J, Murio C, Heredia J, Working Group on COPD, Spanish Society of Internal Medicine. Short- and medium-term prognosis in patients hospitalized for COPD exacerbation: the CODEX index. Chest. 2014;145:972-80.

31. Price LC, Lowe D, Hosker HS, Anstey K, Pearson MG, Roberts CM, Society BT, the Royal College of Physicians Clinical Effectiveness Evaluation Unit (CEEu). UK National COPD Audit 2003: Impact of hospital resources and organisation of care on patient outcome following admission for acute COPD exacerbation. Thorax. 2006;61:837-42

32. Roberts CM, Lopez-Campos JL, Pozo-Rodriguez F, Hartl S, on behalf of the European COPD Audit team. European hospital adherence to GOLD recommendations for chronic obstructive pulmonary disease (COPD) exacerbation admissions. Thorax. 2013;68:1169-71.

33. López-Campos JL, Hartl S, Pozo-Rodriguez F, Roberts CM, on behalf of the European COPD Audit team. Variability of hospital resources for acute care of COPD patients: European COPD audit. Eur Respir J. 2013;41:270-6.

\section{Submit your next manuscript to BioMed Central and we will help you at every step:}

- We accept pre-submission inquiries

- Our selector tool helps you to find the most relevant journal

- We provide round the clock customer support

- Convenient online submission

- Thorough peer review

- Inclusion in PubMed and all major indexing services

- Maximum visibility for your research

Submit your manuscript at www.biomedcentral.com/submit 